\title{
Recursos culturales turísticos territoriales versus despoblación en Málaga
}

Sergio Reyes-Corredera | grupo de investigación HUM-776 Análisis Geográfico, Dpto. de Geografía, Universidad de Málaga

URL de la contribución <www.iaph.es/revistaph/index.php/revistaph/article/view/4493>

La cuestión que atañe a este debate es cuanto menos particular ya que pone en alza el concepto patrimonio de la humanidad que, como se sabe, no pretende más que resaltar la excepcionalidad de un ente que puede ser físico y/o cultural por sus valores excepcionales reconocidos por la comunidad internacional. Se podría plantear la cuestión sobre qué es más excepcional para una comunidad ¿su patrimonio cotidiano o local el cual entra en su imaginario, vincula con sus experiencias vitales y no desea que desaparezca porque con él pueden destruirse una parte de sus recuerdos... o las declaraciones de lo que está ya ratificado a nivel mundial? Esto hace cuestionarse que la realidad lleva a hablar de escalas de las relaciones sociales y de las comunidades vinculadas con el patrimonio donde quizá una comunidad grande (en número de habitantes) puede no reconocer estos valores excepcionales mientras que una pequeña puede mostrar más arraigo debido a esta relación de escalas con estos entes percibidos. En relación con esta idea, las pequeñas comunidades o sociedades locales del medio rural en ocasiones pueden verse afectadas por cuestiones como la difícil accesibilidad y conexión con otros espacios que prestan los servicios de los que precisan para disponer de una economía algo más diversificada y que podría estar en valor y ser promocionada a través de su patrimonio local y utilizarlo como un factor impulsor y generador de economía basada en la cultura sin tener que apostar por un único recurso modelo "gallina de los huevos de oro". Por ello es necesario realizar unos buenos diagnósticos territoriales y turísticos que den visibilidad a ese tejido patrimonial que fomente la perpetuación de esa comunidad en su tierra.

Por otro lado, la pérdida de la identidad de la comunidad conlleva una pérdida de la importancia del patrimonio para su población. El patrimonio es algo muy señero

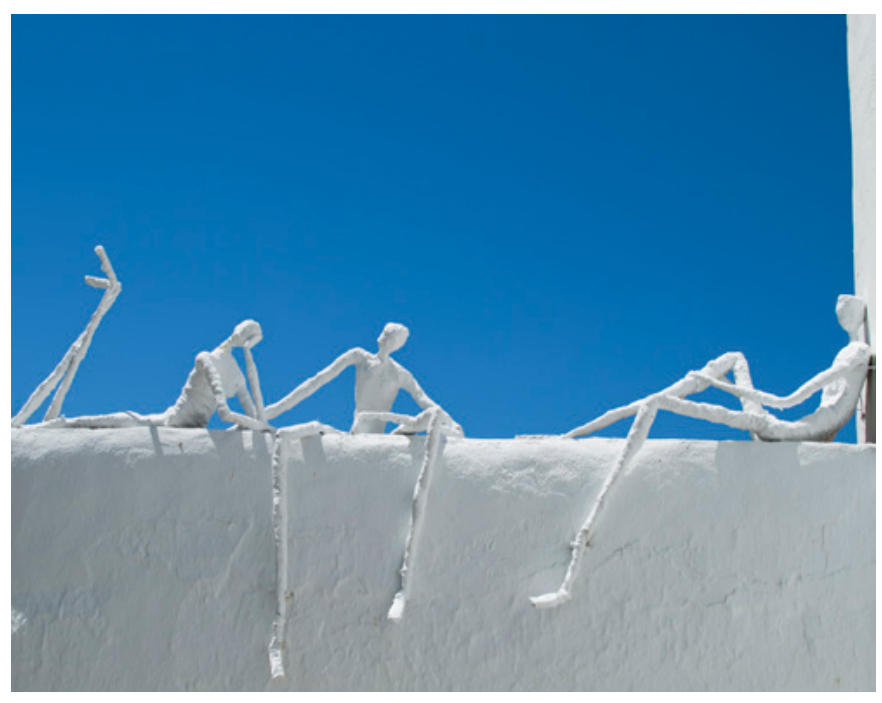

Una de las muchas obras que se pueden ver y disfrutar paseando por las calles de Genalguacil, el pueblo museo de Andalucía, 2014 | foto Ángeles Andrade

de la comunidad y forma parte de su orgullo, aunque en muchas ocasiones pueda rozar o alcanzar el chovinismo. Pero no verán aceptación en una comunidad consolidada si la iglesia de su pueblo presenta desconchones en su fachada; seguramente la siguiente acción sea reclamar a los representantes de la corporación local o eclesiásticos su encalado.

Otro aspecto que es preciso resaltar es la distancia entre lo urbano y lo rural en cuanto a la diferencia de servicios básicos clave, desde la fibra óptica hasta la disponibilidad de colegios para fomentar la fijación de la población. En definitiva, el medio rural tiene que ser una buena alternativa de vida a los espacios urbanos y estas alternativas deben contemplar también la cultura local y, por supuesto, las tendencias actuales del arte contemporáneo y las performances más habituadas al espacio urbano. En este sentido se puede destacar el ejemplo 
a debate ¿Hay patrimonio sin comunidad? Despoblamiento, turistificación y patrimonio cultural

| coordina Jaime Jover Báez

del municipio de Genalguacil (Málaga), rompiendo con todos los marcos habituales del medio rural con relación al arte contemporáneo y convirtiendo, con un gran respeto a lo tradicional, en un museo sus vías públicas y sus fachadas. Esta transformación, que ha despertado el interés de curiosos y atrae a artistas de diferentes puntos geográficos, ha situado en el mapa del arte actual este pequeño municipio de unos 400 habitantes aprovechando su situación intermedia entre la ciudad patrimonial de Ronda y uno de los principales destinos turísticos mundiales: la Costa del Sol Occidental.

A vueltas con lo urbano, el poblamiento en los centros históricos se está viendo mermado debido a fenómenos como los alquileres vacacionales o su puesta en valor, en este segundo caso de un modo paradójico para la población residente, ya que toda mejora realizada está fomentando su expulsión por su implementación del atractivo turístico. No obstante, este fenómeno está fomentando la creatividad y la generación de patrimonio contemporáneo en las periferias inmediatas a las almendras históricas de las ciudades que pueden manifestarse en forma de murales y/o actuaciones voluntarias vecinales partiendo algunas de estas iniciativas desde las comunidades universitarias relacionadas con las bellas artes o la arquitectura, como son los casos del SOHO o barrio de las artes o el barrio de Lagunillas en la ciudad de Málaga con mayor y menor apoyo municipal, respectivamente.

Por último, es necesario remarcar que, con la pérdida de identidad o de la relación con el barrio, también desaparecen las relaciones sociales y económicas, ya que no sería posible defender las actuaciones negativas sobre el patrimonio si no se reconoce el valor del mismo en la comunidad a la que se pertenece, aunque este valor no sea patrimonial pero sí identitario. En el caso de la ciudad de Málaga se ha vivido recientemente con el derribo de la conocida como La Mundial, una antigua pensión que disponía de unos valores históricos, arquitectónicos y paisajísticos urbanos que han sido obviados por una actuación del arquitecto Moneo con el visto bueno y democrático de la cámara municipal y el beneplácito de la gerencia de urbanismo del municipio, incluyendo una descatalogación de este bien. Esta dinámica de derribo de edificios que representan el paisaje urbano clásico de los centros históricos, en el caso de Málaga dominado por las fachadas de los siglos XVIII y XIX, pero que como el que se compra un cuadro de un pintor contemporáneo en alza se olvida de otros valores patrimoniales y quita un Cézanne de la pared, va a conllevar una modernidad que no vendrá acompañada de la identidad local. Esta despoblación sin duda ha sido uno de los condicionantes de esta existente pero escasa reivindicación a favor de la gestión y protección del patrimonio local del centro histórico de Málaga.

\section{BIBLIOGRAFÍA}

- CONVENCIÓN sobre la protección del patrimonio mundial, cultural y natural (1972) UNESCO. <https://whc.unesco.org/ archive/convention-es.pdf> [Consulta: 15/07/2019]

- GENALGUACIL y sus encuentros de arte (2018) [en línea] Ayuntamiento de Genalguacil <http://www.genalguacil.es/es/Ar te_y_cultura/Encuentros_de_Arte/Presentacion>[Consulta: 15/ 07/2019]

- LAGUNILLAS. El arte urbano de Málaga sin restricciones.. Street Art Málaga [en línea] <https://www.streetart malaga.com/tour/lagunillas> [Consulta: 15/07/2019]

- RUIZ PADRÓN, L. (2019) La hora crítica de La Mundial. luisruiz.es: blog heterodoxo sobre dibujos urbanos, martes 12 de marzo de 2019 <http://luisrpadron.blogspot.com/2019/03/ la-hora-critica-de-la-mundial.html> [Consulta: 15/07/2019]

- RUIZ PADRÓN, L. (2015) La Mundial y el progreso. La Opinión de Málaga [en línea], 31 de octubre de $2015<$ https:// www.laopiniondemalaga.es/opinion/2015/10/31/mundialprogreso/805670.html> [Consulta: 15/07/2019]

- SOHO Málaga Barrio de las Artes. Ayuntamiento de Málaga <http://soho.malaga.eu> [Consulta: 15/07/2019] 